histological reports mentioned all the signs in UC or CD either as positives or relevant negatives. The importance of good histological reporting may help clinicians in differentiating between the different IBD types which in turn may help guide optimum evidence based management.

Competing interests None declared.

\section{PMO-237 PREBOTICS AS PRIMARY PREVENTION OF CROHN'S DISEASE: IMPACT ON LUMINAL MICROBIOLOGY AND ELEVATED FAECAL CALPROTECTIN IS GREATER IN HEALTHY SIBLINGS THAN IN PATIENTS}

doi:10.1136/gutjnl-2012-302514b.237

${ }^{1,2} \mathrm{C}$ R Hedin, ${ }^{*} \mathrm{P}$ Louis, ${ }^{3} \mathrm{~F}$ Farquharson, ${ }^{4} \mathrm{~S}$ McCartney, ${ }^{2} \mathrm{~A} J$ Stagg, ${ }^{2} \mathrm{~J} 0$ Lindsay, ${ }^{1} \mathrm{~K}$ Whelan. ${ }^{1}$ Diabetes and Nutritional Sciences Division, King's College London, London, UK; ${ }^{2}$ Blizard Institute, Queen Mary University of London, London, UK; ${ }^{3}$ Microbiology Group, Rowett Institute of Nutrition and Health, University of Aberdeen, Aberdeen, UK; ${ }^{4}$ Department of Gastroenterology, University College Hospitals NHS Foundation Trust, London, UK

Introduction Inflammation in Crohn's disease (CD) is driven by the intestinal microbiota, however, microbial manipulation with prebiotics is ineffective in treating active disease. ${ }^{1}$ Siblings of patients are at risk of developing $\mathrm{CD}$, and some share aspects of the $\mathrm{CD}$ phenotype including raised faecal calprotectin (FC) and dysbiosis. Prebiotics may alter these risk markers.

Methods Patients with inactive CD ( $\mathrm{n}=19, \mathrm{CD}$ activity index $<150)$ and 12 unaffected siblings ingested $15 \mathrm{~g} / \mathrm{d}$ of fructo-oligosaccharide/ inulin (FOS) for 3 weeks. FC (enzyme-linked immunosorbant assay) and faecal microbiota (quantitative PCR targeting $16 \mathrm{~S}$ ribosomal RNA (rRNA) genes, quantified relative to representative bacterial $16 \mathrm{~S}$ rRNA genes) were measured at baseline and follow-up. Nonparametric statistical analyses were performed, and values presented as medians.

Results In patients and siblings, Bifidobacteria and Bifidobacterium longum increased post-FOS. In siblings but not patients, Bifidobacterium adolescentis and Roseburia spp. also increased (Abstract PMO237 table 1). Compared with patients, siblings had a greater median percentage point change in Bifidobacteria $(+14.6 \%$ vs $+0.4 \%$, $\mathrm{p}=0.028), B$ adolescentis ( $+1.1 \%$ vs $0.0 \% \mathrm{p}=0.006)$ and Roseburia spp. $(+1.5 \%$ vs $-0.1 \% \mathrm{p}=0.004)$. Of those with raised $\mathrm{FC}$ at baseline, it decreased post-FOS in only $7 / 19$ patients (37\%), compared with $4 / 5$ $(80 \%)$ siblings $(p=0.142)$. The change in FC was significantly negatively correlated with baseline FC in siblings ( $\mathrm{r}=-0.715$, $\mathrm{p}=0.009$ ) but positively correlated with baseline $\mathrm{FC}$ in patients $(\mathrm{r}=+0.352, \mathrm{p}=0.140)$.

Abstract PM0-237 Table 1 Microbiota at baseline and follow-up

\begin{tabular}{lllll}
\hline $\begin{array}{l}\text { Bacteria Concentration } \\
\begin{array}{l}\log _{\mathbf{1 0}} / \mathbf{g} \text { dry faeces, } \\
\text { median (IOR) }\end{array}\end{array}$ & Baseline & $\begin{array}{l}\text { Follow-up } \\
\text { (post F0S) }\end{array}$ & p Values \\
\hline Bifidobacteria & Patients & $9.4(2.0)$ & $9.7(1.3)$ & 0.013 \\
& Siblings & $9.9(0.6)$ & $10.3(0.5)$ & 0.028 \\
B longum & Patients & $9.0(3.4)$ & $9.4(2.1)$ & 0.036 \\
& Siblings & $9.1(3.5)$ & $9.6(2.8)$ & 0.008 \\
B adolescentis & Patients & $5.2(4.4)$ & $5.2(9.5)$ & 0.831 \\
& Siblings & $9.0(4.2)$ & $9.1(3.8)$ & 0.012 \\
Roseburia spp. & Patients & $9.2(1.9)$ & $8.9(4.3)$ & 0.198 \\
& Siblings & $9.3(3.2)$ & $9.6(0.8)$ & 0.023 \\
\hline
\end{tabular}

Conclusion In contrast to inflamed $\mathrm{CD},{ }^{1}$ a prebiotic effect with $\mathrm{FOS}$ occurs to a limited extent in non-inflamed CD, and also occurs, more markedly, in at-risk siblings. Furthermore, FC decreased in siblings post-FOS, but did not change significantly (and even tended to rise) in patients with inactive CD. Prebiotics may best be employed in disease prevention rather than treatment.

Competing interests C Hedin: Grant/Research Support from: Clinical Research Fellow funded by Core charity, P Louis: None declared, F Farquharson: None declared, S McCartney: None declared, A Stagg: None declared, J Lindsay: None declared, K Whelan: None declared.

\section{REFERENCE}

1. Benjamin JL, Hedin CR et al. Gut 2011;60:923-9.

\section{PM0-238 BLOCKADE OF THE B7 INTEGRIN PREVENTS ADHERENCE OF T LYMPHOCYTES TO MADCAM-1 IN AN IN VITRO MODEL OF VASCULAR MICROCIRCULATION POST- CAPILLARY SHEAR FLOW}

doi:10.1136/gutjnl-2012-302514b.238

C A Lamb, ${ }^{*}$ G O'Boyle, D E Jones, J C Mansfield, J A Kirby. Institute of Cellular Medicine, Newcastle University, Newcastle upon Tyne, UK

Introduction The intestinal vascular microcirculation plays a pivotal role in the immune cell dysregulation that drives inflammatory bowel disease. $T$ lymphocyte recruitment, adherence and migration are dependent on the integrin heterodimer $\alpha 4 \beta 7$, which binds with high affinity to vascular endothelium expressing MAdCAM-1, prior to lymphocyte diapedesis into the lamina propria. This integrin therefore provides a potential therapeutic target.

Methods Using Cellix ${ }^{\circledR}$ technology, a dynamic in vitro model was created, testing the potential of $\beta 7$ integrin blockade to impair lymphocyte adhesion to MAdCAM-1 under shear flow. The Cellix ${ }^{\circledR}$ system comprises a microfluidic platform and nano pump, with biochip channels that replicate the shear flow and stress found in post-capillary venules. Peripheral blood mononuclear cells (PBMC) were utilised, along with HuT78 T cells that constitutively express the $\alpha 4 \beta 7$ integrin and the chemokine receptor CXCR4, known to be upregulated in inflammatory bowel disease. Biochips were coated for $12 \mathrm{~h}$ at $4^{\circ} \mathrm{C}$ with $10 \mu \mathrm{g} / \mathrm{ml}$ MAdCAM-1 Fc, then blocked with $0.1 \%$ BSA for $30 \mathrm{~min}$ to prevent non-specific adherence to plastic. Adherence of T cells was quantitatively assessed by microscopy at a physiological flow rate of $1 \mathrm{dyne} / \mathrm{cm}^{3}$. The effect of an anti-human $\beta 7$ integrin monoclonal antibody (clone Fib504, BD Pharmingen) on lymphocyte adherence was measured. $3 \mathrm{nM}$ of the chemokine CXCL12 (ligand for CXCR4) was added to the system to model the pro-inflammatory environment present in inflammatory bowel disease. Experiments were performed at $37^{\circ} \mathrm{C}$.

Results HuT78 lymphocytes and PBMC $\left(5 \times 10^{6} / \mathrm{ml}\right)$ provided consistent adherence to MAdCAM-1 under flow, mean \pm SE adherent cells/hpf of $32.8 \pm 4.5$ and $46.2 \pm 3$ respectively. Adherence was significantly improved with the addition of $3 \mathrm{nM}$ CXCL12 to $45.7 \pm 2.8(p<0.05)$ and $78.5 \pm 1.5(p<0.001)$. Incubating the cells with the Fib504 anti- $\beta 7$ integrin antibody, led to a significant reduction in adherence of unstimulated cells to $17.8 \pm 2(p<0.001)$ and $18 \pm 3.2$ $(p<0.0001)$. This reduction was maintained on stimulation with CXCL12, at $17.3 \pm 0.9(p<0.001)$, and $5.3 \pm 0.9(p<0.0001)$.

Conclusion This novel in vitro model, demonstrated significant modulation of $\alpha 4 \beta 7$ lymphocyte adhesion to the ligand MAdCAM-1 with an anti- $\beta 7$ antibody. This highly controlled model system provides a more physiological representation of chemokine driven responsiveness than previously published chemotaxis or adhesion assays, and thus the Cellix ${ }^{\circledR}$ platform may serve as a useful tool for the development and validation of future anti-lymphocyte adhesion therapeutics. This research supports the clinical investigation of therapeutics targeting the $\beta 7$ subunit or $\alpha 4 \beta 7$ heterodimer in this disease setting.

Competing interests None declared. 